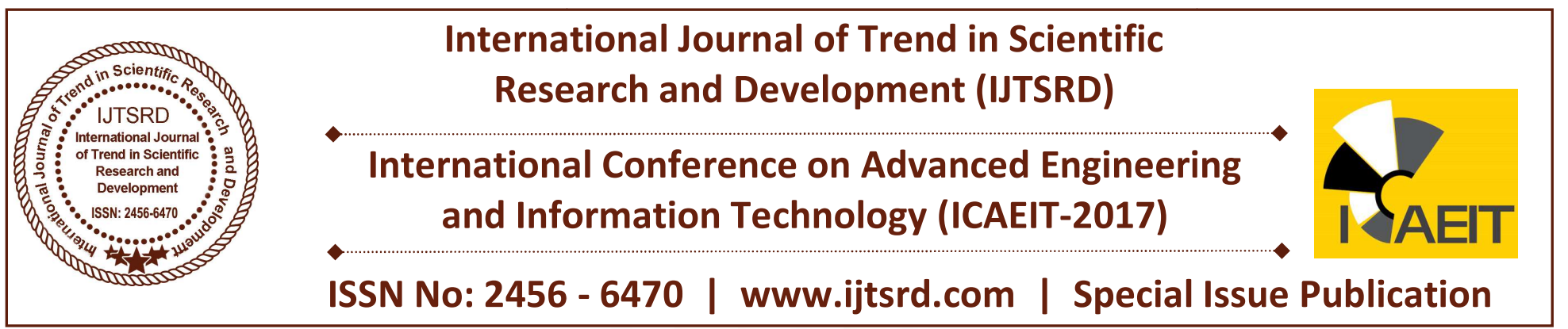

\title{
Web Based Tool for Managing Paddy Irrigation Water User Group
}

\author{
Deepak T. J. ${ }^{1}$, Chong S. F. ${ }^{2}$, Lim S. P. ${ }^{2}$ \\ ${ }^{1}$ Associate Professor, Dean Faculty of Engineering and Technology, \\ Linton University College, Mantin, Negeri Sembilan, Malaysia \\ ${ }^{2}$ G \& P Water Sdn Bhd, Wisma G \& P, Bandar Tasik Selatan, Kuala Lumpur, Malaysia
}

\section{ABSTRACT}

In many countries, the Internet has become an element in people's daily life, offering new possibilities for information access and sharing. In this new technological and information age, water is becoming a source of conflict between domestic, industrial and agricultural use. Web Based Tool is a platform allowing for a public participation in helping decision making processes during conflicting situations, especially in cases involving many stakeholders. A 3 - tier architecture framework was carefully studied and was implemented to create the Web based model. This model is an Internet Based Model that is created to benefit the users in the water management sectors in order to make timely decisions to develop the water user group's inline with the tertiary canal. This system has been successfully developed to estimate the water productivity index and $\mathrm{pH}$ of soil on a micro scale based on the tertiary canal water user groups with the plot numbers alongside to allocate water without wastage. This system has the ability to provide access to those users with password who has the technical capabilities to connect to the Internet, hence bridging the digital divide between rural and urban communities.

Keywords: Internet, Web, Water Management, Water Productivity Index, PH, Decision Making.

\section{INTRODUCTION}

In many countries, the Internet has become an element in people's daily life, offering new possibilities for information access and sharing. At the same time there are growing concerns that not only technical specialists and government officials should be involved in decision making associated with utilization of natural resources. Many groups within the society express the willingness and desire that they also want to be actively involved in decision making. This creates challenges to the researchers and forms a new situation confronting those actively involved in development of models and tools applied for decision making. WEB PIPA is a decision support system created to enhance the users to be involved in data input as well as decision making process. The recent advancement in the field of Internet has opened up new challenges as well as opportunities in the way we have been developing models and decision support aids. It is not only the medium of information access and communication but also a flourishing platform to develop new generation of applications. With the emergence of revolutionary technology of web, now it has become possible to develop information systems distributed across different locations and heterogeneous platform. This holds great promise for application in the food and agricultural systems which is highly diversified

In this technological and information age, water is becoming a source of conflict between domestic, industrial and agricultural use. In Malaysia, irrigation has been exclusively devoted to the cultivation of rice paddy. The total land area planted with rice is about 600,545 ha of which 340,618 ha are supported by irrigation systems. The remaining area depends mainly on rainfall (APO, 1991). Irrigation water management is becoming a challenging issue. More importance has been given towards the improvement and effective management of water for the irrigation. Water is important for rice irrigation and it is scarcely available in some of the areas. Hence management of 
water becomes very important to cultivate rice. A good irrigation water management system has to be provided to give adequate and timely supply of water to improve the crop production. In order to achieve this, it is necessary to have adequate water source, a good conveyance system and good distribution system to distribute the water over the land. The agricultural scientific community has been developing models, databases, expert systems, decision support systems and software. The WEB PIPA is an example of DSS created to provide an effective conduit for the transfer of scientific knowledge from research labs to the endusers to support them in decision making.

\section{Study Area}

The selected study area is the Tanjung Karang Rice Irrigation Project. The project area is located on a flat coastal plain in the Northwest Selangor Agricultural Development Project (PBLS). It is in the districts of Kuala Selangor and Sabak Bernam, which cover an area of approximately 20,000 hectares extending over a length of $40 \mathrm{~km}$ along the coast with a average width of $5 \mathrm{~km}$. The main irrigation and drainage canals run parallel with the coast. The Bernam River is the main water source for the project area. Water for the Tanjung Karang scheme is diverted from the Bernam River Head works (BRH), and the Bagan Terap Pump house, situated about $130 \mathrm{~km}$ and $62 \mathrm{~km}$ respectively upstream of the mouth of the Bernam
River. The project area is divided into eight irrigation compartments and into four Irrigation Scheduled Areas (ISA) as shown in Figure 1 below.

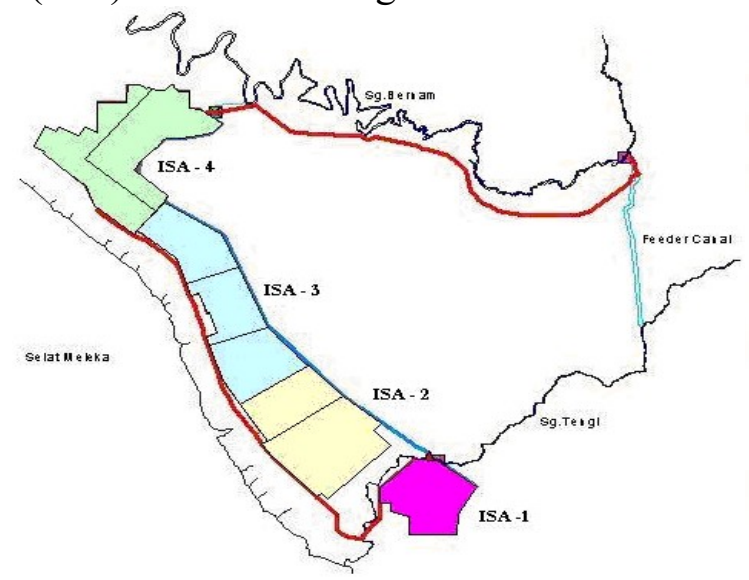

Fig 1: Irrigation Scheduling Areas in Tanjung Karang Irrigation Scheme

In the upstream six irrigation compartments from Sawah Sempadan to Sungai Nipah, tertiary canals are directly connected to the main canal. About 50 farm lots are grouped in one sub-block. Out of the 19,247 ha. total area, paddy fields comprise 17,510 ha. The remaining area of about 1,737 ha. comprises vegetable growing 760 ha, tree cropping 460 ha, and idle land 510 ha. The annual yield of paddy is about 166,700 metric tons a year. The schematic diagram of the study area is given below;

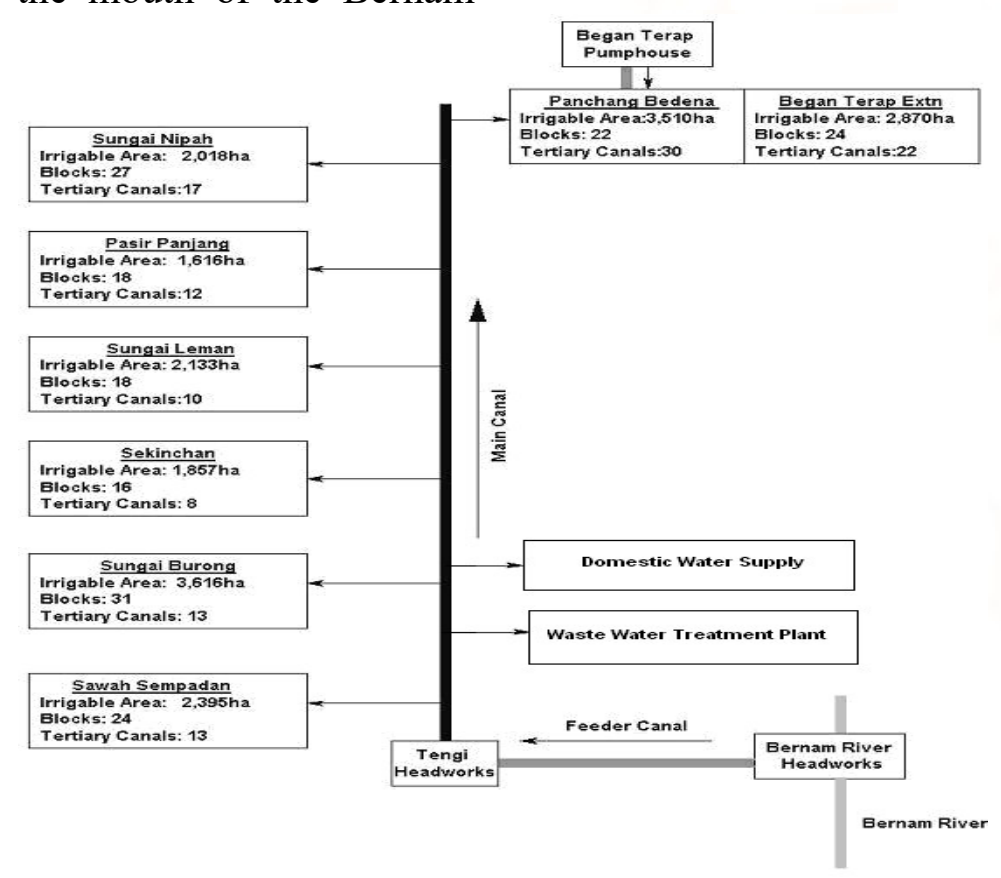

Fig 2: Schematic diagram showing the study area with compartment details

Earlier study SMHB (1995) have acquired field data with respect to compartments and have calculated the irrigation parameters, whereas this study has emphasized data with respect to blocks and calculate the irrigation parameters. For more precise management, tertiary canals and $\mathrm{CHO}$ discharges 
should be considered with respect at block level for calculating the irrigation parameters to properly manage the irrigation scheme. This study mainly emphasized on the application of Internet to acquire more data for a better decision support system.

\section{Methodology}

This is one of the modules that are created along with three other Web based modules to determine the Water Productivity Index for paddy at a particular lot in the block. Fig 3, clearly shows the step by step procedure for analysis of Water User Group Webpage Module.

Designing this module was very important from researcher's point of view since most of the water managers and government officials do not know the net rice yield that is produced and sold by a particular lot in the study area until much later. This study emphasized in designing a web based program where farmers or farm heads are allowed to key in the accurate yield data from their lots.

During this study, farmers reported that it was difficult for them to key in the data through the internet. Keeping this in view, a MS Excel spreadsheet was created for the farmers, so that they could key in the yield data. Once the yield data is keyed into the MS Excel spreadsheet which is based on whole season (Main season/Off season), for a particular subdivided block, it is then accessed through admin id. In admin id, there is an option to directly upload the spreadsheet into the Water User Group Webpage Module.

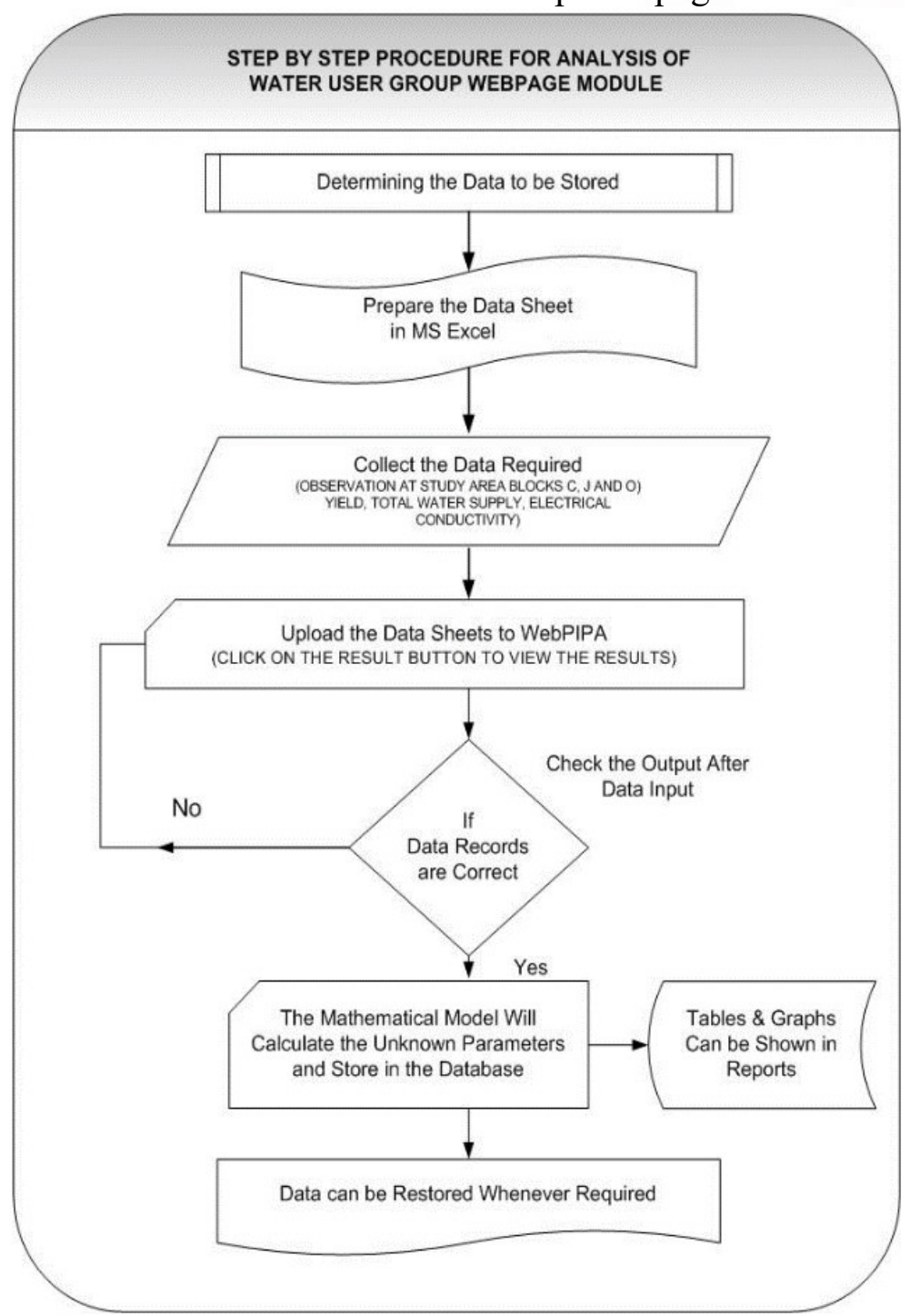

Fig 3: Step by Step Procedure for Analysis of Water User Group Webpage Module

In this module the beginning stage is to determine the data that has to be stored in database for future use and once it is confirmed, the data has to be collected which is required for this particular web page design. In this module there are two options, one is to key in directly and other option is to upload through MS 
Excel spreadsheet directly through admin page. After data collection, user interface is to be designed according to the requirement; normally a user-friendly environment is designed. In this study, interactive Web Pages are created for user interface to login using User ID and Password. After login, the data is fed in the correct place and results are obtained. Once the results are obtained, check them for accuracy. If the results are accurate click on the save button and save the data fields in the WEB SQL database.

The data stored in the WEB SQL database can be checked, viewed and edited if required in the station user mode (suser). The data can be only viewed in station user1 mode (suser1) and in administrator mode (admin) for this module. Administrator Id has the authority to delete or add more data files through the WEB based program. External data from MS Excel spreadsheet can be directly uploaded through this module to WEB SQL database. In this module the graph reports can be seen through the administrator user id.

\subsection{Water Productivity Index:}

The water productivity index measures effectiveness of the irrigation system in terms of gross rice yield and the total volume of water applied. The realistic range of the water productivity index should be from 0.30 to $0.60 \mathrm{~kg} / \mathrm{m}^{3}$. In order to increase the rice yield per hectare and also to upgrade the water use efficiency, it is very much important to improve the water productivity index. It is expressed below,

$$
W P I=\frac{Y}{Q_{S} * 10,000} \mathrm{Kg} / \mathrm{m}^{3}
$$

WPI: Water Productivity Index

Y: Yield

$\mathrm{Q}_{\mathrm{s}}$ : Discharge

\section{2 pH Value:}

The $\mathrm{pH}$ of the soil affects plant production. Irrigation water or precipitation can change the $\mathrm{pH}$ of the soil overtime. Nutrients present in the soil may be unavailable to the plants due to a $\mathrm{pH}$ that is either too high or too low. Here ${ }_{\mathrm{P}} \mathrm{H}$ is expressed by correlating to $\mathrm{E}_{\mathrm{c}}$ of shallow soil.

$$
{ }_{\mathrm{PH}}=4.899-0.0042 \mathrm{EC}_{\mathrm{as}}+1 \times 10^{-4} \mathrm{EC}_{\mathrm{as}}{ }^{2}
$$

\subsection{WEB Based Water User Group DSS}

This system is a standalone executable application. A 3 - tier architecture framework was carefully studied and was implemented to create the system. Web model is an Internet Based System that is created to benefit the users in the water management sector in order to make timely decisions on irrigation water supply. Web Model has the ability to provide almost unlimited access to information to everybody, who has the technical capabilities to connect to the Internet. This makes Web model particularly suitable for providing and disseminating information relevant to decision making processes concerning management of irrigation water resources. Specifically, Web model may be seen as a platform allowing for a public participation in resolving decision making processes involving many stakeholders and different water user groups. In such situations, access to neutral and unbiased source of information about consequences of possible policy and/or management strategies may contribute to constructive dialogue between parties involved and consequently help to overcome differences of positions dividing the parties and reach (if not an agreement), then at least reasonable compromise.

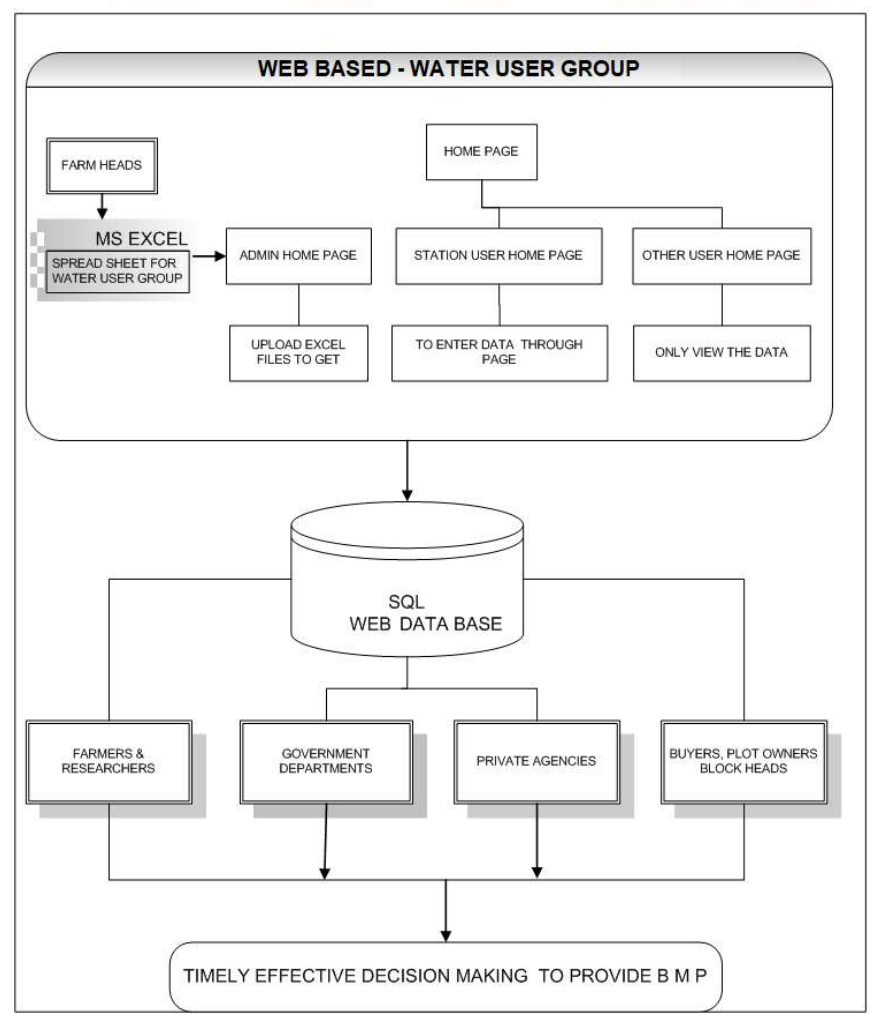

Fig 4: Web Based Water User Group Model

\section{Results}

The results derived from the program would be a major boost for the decision makers to make precise decisions on issues concerned to the Water User Group. The input parameters that are to be fed in to the program and output parameters obtained are shown in the figure 5. 
International Journal of Trend in Scientific Research and Development (IJTSRD) | ISSN: 2456-647

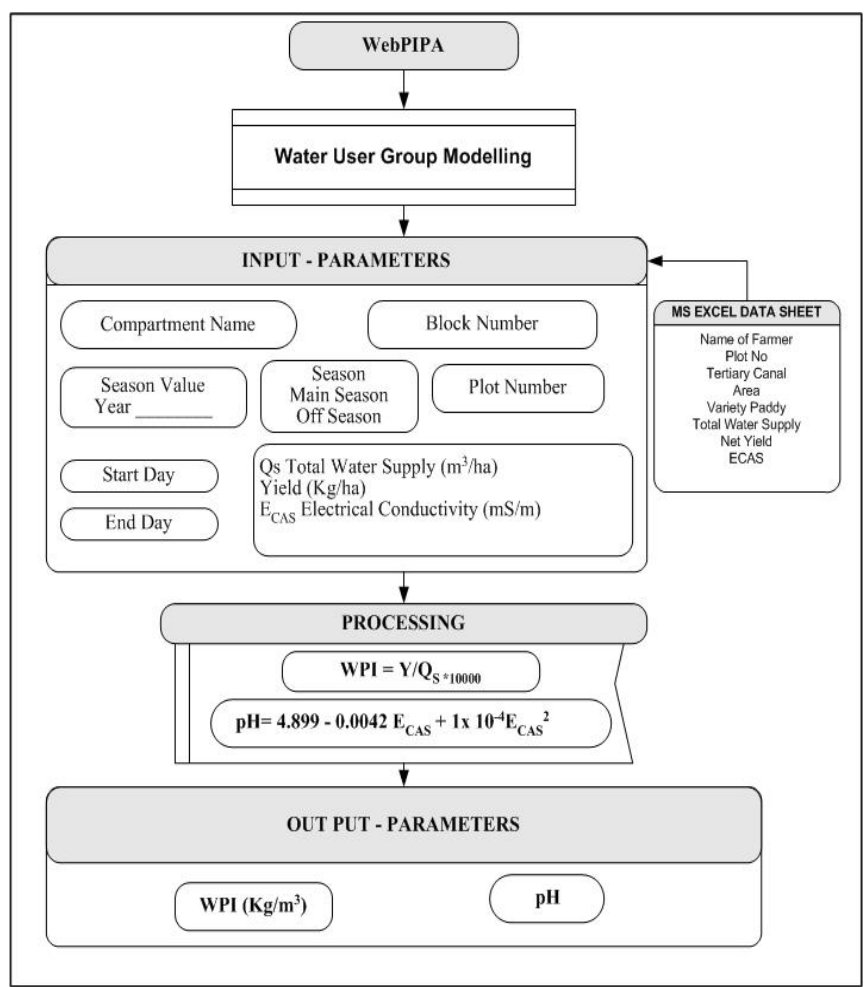

Fig 5: Input and Output Parameters for Web Based Water User Group

The Water User Group model is created to determine the Water Productivity Index (WPI) and $\mathrm{pH}$ value in the webpage. Figure 5, shows the input parameters and output parameters clearly. The MS Excel spreadsheet will be uploaded through this webpage with administrator id only as an input. Output parameters are viewed in the webpage through the Web SQL database in all three different user modes.

Figure 6 illustrates the results of water user group webpage outline for the admin users. The results shown here can only be viewed. The administrators will not be able to edit this webpage. The input parameters are uploaded through MS Excel database in the administrator mode. The uploaded data can be viewed in the above shown format in this webpage option.

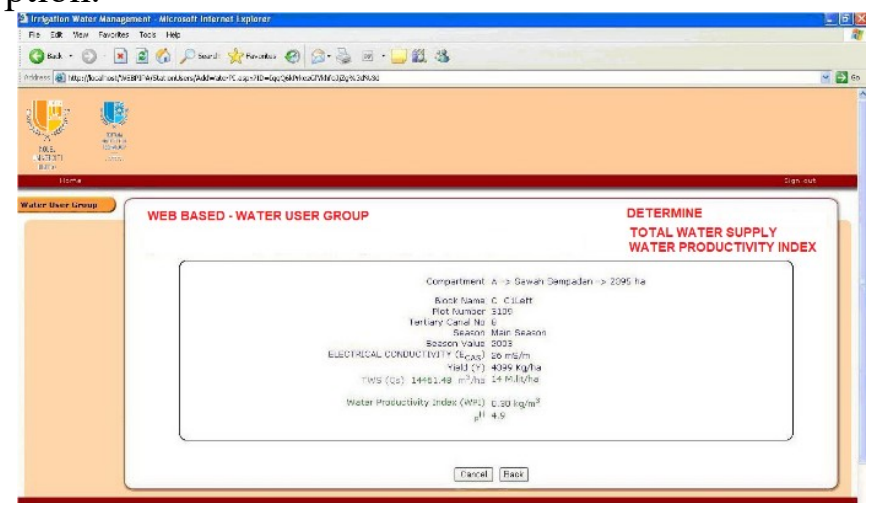

Fig 6: Web Page showing the results for Web Based Water User Group

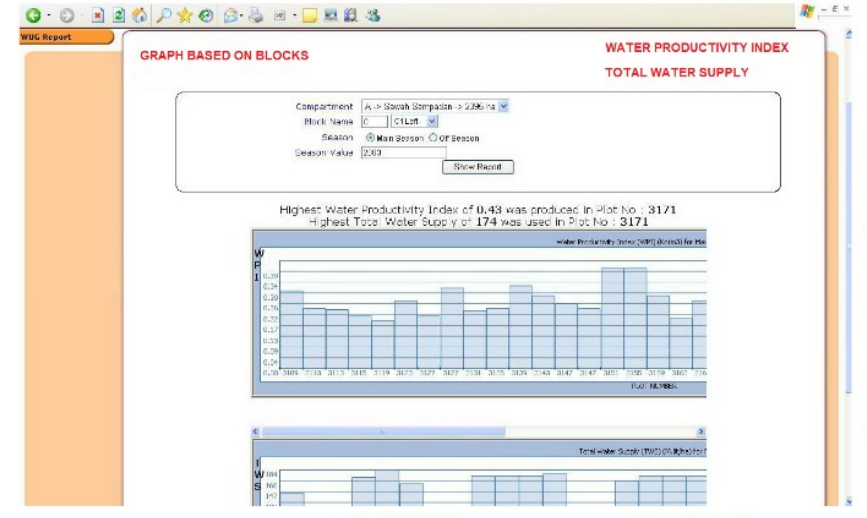

Fig 7: WUG Report Webpage

Figure7 illustrates the WUG report webpage option for the admin users. In this page the administrator selects the compartment, block name, season and year which is denoted by season value. Once the block name is typed in the text box, there is scroll down option where the subdivision of the block (for example: Block C, sub blocks C1left, C1right, C2left and $\mathrm{C} 2$ right) can be entered. After entering the required parameters by clicking the show report button and the graph report can be viewed on this same webpage

\section{Conclusion}

The Web based system has been successfully developed to estimate the water productivity index (once in 6 months frequency?) and $\mathrm{pH}$ of soil (who measures? How? Frequency? Actions after measurements?) on a micro scale based on the tertiary canal water user groups with the plot numbers alongside to allocate water without wastage (How is wastage reduced with this web-based module?).

The "Water User Group" module was developed to give information on various parameters such as Water Productivity Index and $\mathrm{pH}$ value of soil. This module helps the decision makers in understanding the status of the plot based on the Water supplied and the Water Productivity Index achieved for a particular season. This module also shows the $\mathrm{pH}$ value of the soil for the particular season. Based on the results obtained the decision makers can conclude various aspects and from there future decisions made on Water allocation should benefit the farmers.

This Web based system is particularly suitable for providing and disseminating information relevant to decision making processes concerning management of irrigation water (How? Been practiced then? Still been used to-date? How to know the water supplied to 
each plot? Useful to compute Irrigation Efficiency of block and plot if water supplied could be measured). The Web based platform allows public participation in assessing the water productivity index and $\mathrm{pH}$ of soil. It also has the ability to provide access to those users with password who has the technical capabilities to connect to the Internet, hence bridging the digital divide between rural and urban communities. Decisions made by people who have contributed in its making will be better accepted and implemented towards an improved productivity.

\section{Acknowledgements}

Authors would like to thank the Linton University College and its group of institution's Top Management for their continuous support. University Putra Malaysia and G\&P Water and Maritime is also acknowledged for their continuous support

\section{References}

1. APO, Asian Productivity Organization. Management of Irrigation Facilities, Pg 227. (1991).

2. Booch, G., Object-Oriented Analysis and Design With Applications, Second Edition, The Benjamin/Cummings Publishing Company, Inc., Redwood City, California, (1994).

3. Deepak T. J., MSM Amin, Rashid Sharifff, and Rahman Ramli 2010.- Web PIPA (Web based Paddy Irrigation Productivity Assessment)Decision Support System for Rice Irrigation Water Management, The IUP Journal of Soil \& Water Sciences (India), Vol.III.No.2

4. Fathima. Z. S. \& Dillaha, T. A, Water Management for Lowland Rice Irrigation. J. Irrigation and Drainage Engineering, ASCE, vol.114, no 3:407-423. (1988).

5. Labadie, J., River Basin Network Model for Water Rights Planning, MODSIM: Technical Manual, Department of Civil Engineering, Colorado State University, Fort Collins, Colorado, (1995).

6. Loucks, D. P., Sigvaldason, O. T., Multiplereservoirs Operation in North America, in Z. Kaczmarek and J. Kindler (Eds.) The Operation of Multiple Reservoir Systems, IIASA Collaborative Proceedings Series CP-82-S3 pp. 1 - 104, International Institute for Applied Systems Analysis, Laxenburg, Austria. (1982).

7. Loucks, D. P., Salewicz K., A., Taylor M., R., IRIS - an Interactive River System Simulation
Program, User's Manual Version 1.1. International Institute for Applied Systems Analysis, Laxenburg, Austria, (1990).

8. Ramlee, B. J., Effect of Deep Percolation in Computing Water Use Efficiency for the Paddy Plots. MS Thesis, Serdang, Faculty of Engineering, UPM.( 1992).

9. Shim J., P., Warkentin M., Courtney J., F., Power D., J., Shards R., Carlsson Ch., Past, Present and Future of Decision Support Technology, Decision Support Systems, Nr. 33, pp. 111-126. (2002).

10. SMHB, Syed, Detailed Study of Water Resources Availability Northwest Selangor Integrated Agriculture Development Project, Final Report Vol. 1.( 1995).

11. Zagona E. A., Fulp T., J., Goranflo H., M., Shane R., RiverWare: A General River and Reservoir Modelling Environment, In: Proceedings of the First Federal Interagency Hydrologic Modelling Conference, Las Vegas, NV, pp. 5 - 113. (1998). 